\title{
Prevalence of antenatal depression and its associated factors among pregnant mothers who attend antenatal care service at Jinka public health facilities, Jinka town, SNNPR, Ethiopia,
}

\author{
Aynalem Yetwale ( $\square$ aynalemyetwale@gmail.com ) \\ Jimma University College of Public Health and Medical Sciences \\ Teklemariam Gultie \\ Arba Minch University \\ Dessalegn Ajema \\ Arba Minch University \\ Semahegn Tilahun \\ Mizan-Tepi University \\ Bezawit Afework \\ Arba Minch University
}

\section{Research article}

Keywords: Antenatal depression, pregnant women, Jinka town, Jinka public health institutions

Posted Date: June 15th, 2021

DOI: https://doi.org/10.21203/rs.2.15295/v2

License: (c) (1) This work is licensed under a Creative Commons Attribution 4.0 International License.

Read Full License

Version of Record: A version of this preprint was published on April 16th, 2021. See the published version at https://doi.org/10.1891/IJCBIRTH-D-20-00033. 


\section{Abstract}

Background Antenatal depression is the most common psychiatric disorder during pregnancy and it's associated with psychosocial and obstetric factors. Antenatal depression has serious consequences for the mother and fetus, such as recurrent spontaneous abortions, pregnancy induced hypertension, preeclampsia, postpartum bleeding, pre-term delivery, postnatal depressive disorders and low birth weight. However it doesn't get appropriate attention.

Methods Institutional based cross-sectional study design was conducted on 446 pregnant women coming for antenatal care service at Jinka public health facilities, from June 01 to June 30, 2018. Data was collected through semi-structured and pretested questionnaire by face to face interview technique and Beck Depression Inventory was used to assess women's depression condition. Collected data was entered in to Epi data version 3.3.1 after checking their completeness and exported to statistical package for social science version 20.0 for analysis. Logistic regression was used to find out association between explanatory and response variables. Explanatory variables which fulfill the assumption of logistic regression and had P-value less than 0.25 from bi-variable logistic regression were considered for the multivariable logistic regression model. Strength of association was evaluated using odds ratio at $95 \%$ confidence interval and P-value $<0.05$ was considered to declare significant associations.

Result The magnitude of antenatal depression in this study was $24.4 \%(20.2-28.5$ at $95 \% \mathrm{Cl})$ and it had statistically significant association with unmarried marital status AOR $=13.39$ [(95\% Cl); (3.11-57.7)], chronic medical illness AOR=3.97 [(95\% Cl); (1.07-14.7)], unplanned pregnancy AOR =6.76 [ (95\% Cl); (2.13$21.4)]$, history of abortion $A O R=2.8[(95 \% \mathrm{Cl}) ;(1.14-7.02)]$, history of previous pregnancy complication $\mathrm{AOR}=4.8[(95 \% \mathrm{Cl}) ;(2.12-17.35)]$ and fear of pregnancy related complications AOR=5.4 [(95\% Cl); $(2.32-$ 12.4)].

Conclusion and recommendation The magnitude of antenatal depression was high. So integrating mental health service in antenatal care assessment, provide comprehensive family planning service and improve obstetric service are recommended.

\section{Background}

Depression is a mood disorder that cause persistent feeling of sadness, loss of interest hopelessness, disturbed sleep and disturbed appetite. It's the third leading cause of disease burden worldwide: representing $4.3 \%$ of the total disability adjusted life year. In 2020, depression is predicted to become the second leading cause of the global diseases burden[1] and in 2030, it's expected to be the largest contributor for disease burden. Depression is common in both sex, but its burden is higher in females than males[2]. According to federal ministry of health $(\mathrm{FMOH})$ report in Ethiopia depression contributes about $5 \%$ of the disease burden which is the highest share of burden compared to other forms of mental disorders[3]. 
Pregnancy is normal physiological process in life cycle and being pregnant is a better event for the parents and the society, but it's a time which a woman experiences major physical, physiological and psychological changes which can precipitate or exacerbate depressive tendencies. Hormones which highly produced during pregnancy certainly affect mood as evidenced by estrogen which has been implicated in increased serotonin synthesis, decreased serotonin breakdown, and serotonin receptor modulation[4]. In addition the emotion of a pregnant woman can be affected by different factors, like woman's attitude towards being pregnant, whether or not the pregnancy is planned or wanted, not having formal education, large family size, house wife by occupation, previous pregnancy related complication and the availability of a supportive relationship with a partner $[4,5]$.

According to world health organization report on mental health aspects of women's reproductive health, depression share the highest magnitude as compare to other psychiatric disorder which occur during pregnancy and at least one in ten women in developed countries and two in five women in developing world develop depression during pregnancy[5]. Which is characterized by sad mood, loss of interest, hopelessness, decreased energy, difficulty to think, poor concentration, disturbed sleep and trouble with appetite along with inability to feel happiness, death wish and suicidal thoughts or attempts. $[1,6,7]$.

Antenatal depression can be effectively treated with psychotherapy, cognitive-behavioral therapy, or with medications[4]. Despite, large numbers of women do not get treatment[7], due to low help/care seeking in women with antenatal depression, under detection by health care professionals, and low uptake of antidepressant medications in pregnancy period[8],which increase the impact of untreated depression on the mother, in terms of neglecting her health and increasing the risk of suicide, as well as for the fetus. In addition there is also evidence that untreated antenatal depression is associated with obstetrical complications such as recurrent spontaneous abortion, uterine irritability, pregnancy induced hypertension, preeclampsia, postpartum bleeding, postpartum depression, pre-term delivery and low birth weight $[7,9,10]$.

However, antenatal depression is a common problem with multiple symptoms and impacts on both the mother and the fetus, it doesn't get appropriate attention on early detection and treatment in low and middle-income countries (LMICs). Ethiopia is doing a lot to decrease maternal and neonatal morbidity and mortality and to achieve sustainable developmental goals (SDG 3.1; Reduce the global maternal mortality ratio to less than 70 per 100000 live births by 2030 and SDG 3.2; End preventable deaths of newborns and children under five years of age, with all countries aiming to reduce neonatal mortality to at least as low as 12 per 1000 live births and under-five mortality to at least as low as 25 per 1000 live births by $2030[11]$ ). But a little concern given on the impact of psychological aspects (depression) on obstetrical and neonatal outcome, this may affect the acheivement of sustainable developmental goals.

In different areas of Ethiopia there are different socio demographic and obstetric factors like large family size, low educational status, and low economic status, which contributes for the occurrence of antenatal depression. South omo zone is one of a zone in south nation and nationalities, with the above factors but there is no published information about the problem. 
For all of the reasons listed above, it's better to address the gap in untreated prenatal depression. The first step to address this gap is determining the magnitude of the problem and identify associated factors with it. So this study aimed to assess the magnitude of antenatal depression and associated factors among pregnant women who have ANC follow up in Jinka public health facilities, Jinka town, south omo zone, Ethiopia.

\section{Methods}

\section{Study design}

Institutional based cross-sectional study design was conducted in Jinka town public health facilities, South Omo zone from June 01 to June 30, 2018. South Omo is a zone in the Ethiopian Southern nations, nationalities and peoples region, which is bordered on the south by Kenya, on the southwest by the llemi Triangle, on the west by Bench Maji, on the northwest by Keffa, on the north by Konta, Gamo Gofa and Basketo, on the northeast by Dirashe and Konso, and on the east by the Oromia Region. The administrative center of south Omo zone is Jinka. As a survey from March to April 2008, there were 25804 (male-13160, female-12644) peoples at the time. It has two public health institutions, one health centers and one general hospital. In the hospital there are two psychiatric nurses who provide psychiatric care in outpatient for those having psychiatric problem.

\section{Study participants}

Participants in this study were pregnant women who receiving antenatal care service in the study period at Jinka public health facilities. Eligible participants who were above age 18, verbal consent was taken and for participants who were under the age of 18 written consent was taken from their parents. Pregnant women who were critically ill were excluded in the study.

\section{Sample size determination and Sampling technique}

\section{Sample size determination}

To get the actual sample size, different sample sizes were calculated based on the objectives.

The required sample size for the first objective was determined using a formula for single population proportion by taking $\mathrm{p}$ values from previous study;

- $n=(Z a / 2) 2 p(1-p) / d 2$, as shown in the table below.

- Where; $n=$ Minimum sample size for a statistically significant survey, $z=$ is the significance level (at $5 \%$ significance level its value is 1.96), $p=$ is the magnitude of antenatal depression in Gondar 
university hospital[12], $\mathrm{d}=$ is the margin of error (It has been taken as $4 \%$ ).

Sample Size Determination for the Second Objective

- The sample size for some of the factors for antenatal depression obtained from different studies and calculated by Epi Info 7 menu statically, by considering the following assumptions: confidence level $95 \%$, power $80 \%$ and exposed to unexposed ratio of 1 .

Finally 447 pregnant women were taken which calculated by first objective.

\section{Sampling technique}

There are two public health institutions in Jinka town, one health center and one general hospital. According to their last year June 01 to June 30 ANC service report, 600 pregnant mothers get ANC service in the hospital and 300 pregnant women in health center. Samples were allocated to each public health institutions based on proportional allocation to sample size. By considering last year June 01 to June 30 report as a sample frame $(\mathrm{N})$ which is 900 pregnant women, Systematic sampling technique was used to identify the study unit to participate in the study. The eligible attending respondents were recruited in order of their coming for antenatal service during each day. The first study participant was selected by lottery method using their card number, then every $k$ value $(k=N / n=900 / 447=2$, where $N$ is sample frame, $n$ is sample size for this study and $k$ is regular interval between study participants) were selected based on their order of entry for ANC follow up until reach 447 samples.

\section{Study variables}

\section{Dependent variable}

- Antenatal depression

\section{Independent variables}

- Socio demographic characteristics; Age, Marital status, Educational status, Residence Occupation, Income, and Family size are socio-demographic characteristics.

- Obstetric and other health related variables; Gravida/ Para, trimester of pregnancy, Current pregnancy complications, History of abortion, previous pregnancy related complications, previous labour and delivery complication, and chronic medical illness.

- Psychosocial support; oslo social support scale, husband feeling on pregnancy, and fear of pregnancy, labour and delivery related complications.

- Substance use; Cigarette smoking, Chat, and Alcohol. 
- Previous depression history; history of depression and family history of depression.

\section{Operational definition:}

Antenatal depression: a pregnant women who have mood disorder and scoring 16 or more in beck depression inventory scale[12].

Antenatal care attended: pregnant women who had attended antenatal clinics during the recent pregnancy at least once.

Beck's Depression Inventory is a tool which contains 21 question each with four possible response. Each response assigned a score ranging from 0 to 3 . The overall value of the scale ranges from 0 to 63 , and a pregnant mother with a score of 15 and less was considered as normal while a mother with BDI score of 16 and more was considered as depressed $[12,13]$.

Oslo social support scale: is a three item question which used to assess psychosocial distress. The sum ranging from 3-14 and interpreting as a score of 3-8 (poor support), 9-11 (moderate support) and 1214 (strong support) [14].

\section{Data collection method and instruments}

Data was collected through semi-structured and pretested questionnaire by face to face interview technique. Questionnaire was first prepared in English language and translated into Amharic language and then translated back to English in order to ensure its consistency. Then Amharic version was used for data collection. The questionnaire includes socio demographic characteristics, obstetric history, depression history, substance use, psychosocial and Beck Depression Inventory (BDI) depression screening tool for assessment of depression condition. Six diploma and two BSC nurse professionals who didn't work in the ANC clinic were selected for data collection and supervision respectively and one day training was given about the methodology and questionnaire by the investigator. Data was collected after study participants were get ANC service.

\section{Data quality assurance and analysis}

\section{Data quality assurance}

Data quality was assured before, during and after data collection. Prior to actual data collection, the questionnaire was first prepared in English language and translated into Amharic and then translated back to English in order to ensure its consistency. Pretest was done on $5 \%(25)$ of the sample size in Arba Minch general hospital to determine clarity, adequacy, and efficiency of the questionnaire and corrections 
and modifications taken according to the result and one day training was given for data collectors and supervisors about the methodology and questionnaire by the investigator.

During data collection period the purpose of data collection and importance of the study was told to the participants in order to generate quality data and the collected data were checked for completeness and consistencies by trained supervisors and investigator through close follow up and immediate action were taken accordingly. In addition data collectors were always check participants appointment date on the participant's card to avoid repeated visit. After data collection, the collected data were rechecked for completeness and consistencies by investigator and then multivariable analysis was run in the binary logistic regression model to control the confounding factors.

\section{Data processing and analysis}

Data was entered in to Epi data version 3.3.1 software after coding and checking their completeness and exported to statistical package for social science SPSS version 20.0 for analysis. Descriptive analysis (frequencies, percentage, means and standard deviations) was done to explore socio-demographic, obstetric and other health related characteristics, depression history, substance use and psychosocial characteristics of study participants. Binary Logistic regression was used to find out association between antenatal depression and explanatory variables and explanatory variables which had P-value less than 0.25 and fulfill the assumption of logistic regression from bi-variable logistic regression were considered for the multi-variable logistic regression model. The model goodness of fit was tested by using HosmerLemeshow and Omnibus test and p-value was 0.532 and 0.000 respectively. Strength of association was evaluated using odds ratio at $95 \%$ confidence interval and $P$-value $<0.05$ was considered to declare significant associations.

\section{Results}

\section{Socio demographic}

A total of 446 pregnant women were involved in this study with a response rate of $99.7 \%$ and One hundred ninety-one (42.8\%) study participants were in the age group 20-24, followed by age group 2529 (30\%) with minimum age 16 and maximum 40 and mean age $24.22 \pm 4.45$ years. $422(94.6 \%)$ of pregnant women were married and $348(78 \%)$ mother were live in urban while other $98(22 \%)$ were live in rural.

Regarding their religion $210(47.1 \%)$ mothers were protestant religion follower. More than half of (59.9\%) of pregnant mothers were house wife. $156(35 \%)$ study participants had attended primary school level. Regarding family size $310(69.7 \%)$ of participants had small family size and $38(8.5 \%)$ had large family size while other 97 (21.8\%) participant had average family size with minimum 1, maximum 9,mean 3.82 and standard deviation 1.682 (Table 1) 


\section{Obstetric and other health related characteristics}

In this study participants had an average of 2.61 pregnancies with minimum 1 and maximum 9 . One hundred forty (31.4\%) study participants were primigravida and $410(91.9 \%)$ were planned their current pregnancy. Regarding trimester of pregnancy $211(47.3 \%)$ mothers were in third trimester.

From 306 respondents 32 (10.5\%) had history of previous pregnancy related complications and 16 (5.2\%) had history of labour and delivery complications. On the other $45(15 \%)$ of pregnant women had history of abortion and 37(82.25\%) were aborted spontaneously. Regarding history of chronic medical illness, twenty two (4.9\%) respondents had history of chronic medical illness (Table 2).

\section{Diagnosed history of depression}

Four hundred forty two (99.1\%) study participants had no previous history of depression. Similarly 442(99.1\%) study participants had no family history of depression (Figure 1).

\section{Substance use history of participants}

Four hundred twenty one (94.4\%) study participants had no history of any substance use and from substance users $15(60 \%)$ were chat users and 10(40\%) use alcohol (Figure 2).

\section{Distribution of Psychosocial factors}

Three hundred seventy one (83.2\%) participants had strong social support and $111(24.9 \%)$ had fear of pregnancy, labour and delivery related complication and $34(7.6 \%)$ respondents said their husband were not happy with this pregnancy (Table 3 ).

\section{Magnitude of antenatal depression}

The magnitude of antenatal depression in this study was $24.4 \%[(95 \% \mathrm{Cl}) ;(20.2-285$ (Figure 3).

\section{Factors associated with antenatal depression}

\section{Bi-variable logistic regression}

In bi-variable logistic regression there was statistically significant association between unmarried marital status and antenatal depression. Pregnant women who were unmarried were 6 times more prone to have antenatal depression than those pregnant women who were married COR $=5.8$ [(95\% Cl); $(2.47-13.71)]$. 
Unplanned pregnancy was significantly associated factor which increase the chance of having antenatal depression by seven times COR $=6.67[(95 \% \mathrm{Cl}) ;(3.24-13.70)]$.

Other explanatory variables which had association with antenatal depression in this study were history of abortion COR $=4.06[(95 \% \mathrm{Cl}) ;(2.1-7.85)]$, history of previous pregnancy related complication COR = 5.62 [(95\% Cl); (2.62-12.04)], history chronic medical illness COR $=4.94$ [(95\% Cl); (2.05-11.89)], history of substance use COR $=2.59[(95 \% \mathrm{Cl}) ;(1.139-5.89)]$, fear of pregnancy, labour and delivery complications related complications COR $=8.25[(95 \% \mathrm{Cl}) ;(5.06-13.43)]$, husband feeling to this pregnancy COR $=4.53$ [(95\% Cl); $(2.214-9.28)]$, poor social support COR $=4.77[(95 \% \mathrm{Cl}) ;(1.252-18.2)]$ and moderate social support COR $=2.64[(95 \% \mathrm{Cl}) ;(1.523-4.59)]($ Table 4$)$.

\section{Multivariable binary logistic regression}

In this study pregnant women who were unmarried marital status were 13 times more prone to have antenatal depression than those pregnant women who were married AOR $=13.39[(95 \% \mathrm{Cl}) ;(3.11-57.7)]$. Chronic medical illness was another explanatory variable which increase chance of having antenatal depression by four times AOR $=3.97[(95 \% \mathrm{Cl}) ;(1.07-14.7)]$. Pregnant women who were not plan their pregnancy were seven times more odds to develop antenatal depression compared to those pregnant women who plan their pregnancy AOR $=6.76[(95 \% \mathrm{Cl}) ;(2.13-21.4)]$. On the other pregnant women who had history of abortion were 3 times more likely to develop antenatal depression as compared to those pregnant women who had no history of abortion AOR = 2.8 [(95\% Cl); $(1.14-7.02)]$.

Another explanatory variables which had significant association with antenatal depression in multivariable logistic regression in this study were history of previous pregnancy complication AOR = $4.8[(95 \% \mathrm{Cl}) ;(2.12-17.35)]$ and fear of pregnancy, labour and delivery related complications $A O R=5.4$ [(95\% Cl); (2.32-12.4)] (Table 4).

\section{Discussion}

In this study the magnitude of antenatal depression was $24.4 \%[(95 \% \mathrm{Cl}) ;(20.2-285)]$. It's almost similar with research done in Nigeria 24.5\% [15], Addis Ababa 24.9\%[16] and Gondar University 23\%[12]. However, the finding of this study was higher than research done in Brazil 14.2\%[17], Mumbai 9.6\%[18], Hong Kong $18.9 \%[19]$. This difference might be due to the variation in screening tool used[17, 19], cut off point used for screening[18], year of study and sample size used[17-19].

In the contrary the magnitude of antenatal depression in this study was less than in research done in Greece 28\%[20], Tanzania 33.8\%[21] Maichew 31.1\%[22] Adama hospital 31.2\%[23] wolaita sodo 29.5\% [24] and Arba Minch zuria woreda (26.7\%)[25]. This variation might be due to difference in screening tool used[20, 21, 24, 25], cut off point used for screening antenatal depression[22, 23], socio-demographic, year of study, methodological difference used[24, 25] and sample size used[20-25]. 
In this study unmarried marital status was significantly associated with antenatal depression. Similar finding was reported in study from Nigeria[15], Addis Ababa[16], Michew[22] and Adama[23]. This might be due to unmarried women may feel loneliness, lower self-confidence.

Another explanatory variable which had significant association with antenatal depression was history of chronic medical illness. Consistent finding was reported in study from Brazil[17]. This might be due to chronic medical illness can affect daily activities. It also reduce self-confidence and a sense of hope in the future and leads to feel despair and sadness.

Pregnant women who were not plan their current pregnancy were more likely to have antenatal depression than those pregnant women who plan their pregnancy. Which is in line with study reported from Brazil[17], Mumbai[18], Nigeria[15], Addis Ababa[16], Michew[22], and Adama[23]. This is possible because pregnancy needs physical, psychological and financial preparation and absence of preparation in physical, psychological and financial aggravate pregnancy related physical, psychological and hormonal changes[26].

History of abortion was a significant associated factor which associated with antenatal depression. A consistent finding was reported from Mumbai[18], Greece[20], Adama[23]. This is possible due to psychological consequence of abortion, which range from grief, loss, regret and fear of recurrence, decreased self-esteem, nightmare guilt and anxiety[27].

Another explanatory variable which had significant association with antenatal depression in this study was history of previous pregnancy related complications. This study was supported by study done in Mumbai[18], Nigeria[15], Michew [22] and Arba Minch zuria woreda [25]. This is possible due to physical, psychological and psychiatric side effects of pregnancy related complications, which ranges from fear of recurrence, trigger feelings of worthlessness, isolation and guilt, anxiety to posttraumatic stress.

In this study antenatal depression was high in women who said they fear pregnancy, labour and delivery related complication than mothers who said, they didn't fear pregnancy, labour and delivery related complication. Which is supported by research conducted in Tanzania[21] and Adama[23]. This is possible due to fear of pregnancy, labour and delivery related complication can exacerbate physiological changes which occur during pregnancy, labour and delivery and leads to anxiety[28].

\section{Limitations of the study}

Even though Beck's Depression Inventory screening tool has high sensitivity and specificity to screen depression, it is not diagnostic tool. So diagnosing antenatal depression without psychiatric examination may be difficult. On the other since the study conducted in public health institutions it might be not represent pregnant mothers who get ANC care in private clinic and not attending antenatal care.

\section{Conclusions}


According to this study the magnitude of antenatal depression was high. Nearly one pregnant woman develop antenatal depression in every four pregnant women and unmarried marital status, unplanned pregnancy, history of chronic medical illness, history of abortion, history of previous pregnancy related complications and fear of pregnancy, labour and delivery related complications were factors significantly associated with antenatal depression.

\section{Declarations}

Abbreviations: ANC: Antenatal Care, AOR: Adjusted Odds Ratio, BDI: Beck Depression Inventory, Cl: Confidence Interval, COR: Crude Odds Ratio, LMICs: Low and Middle-Income Countries, OSSS: Oslo Social Support Scale, SDG: Sustainable Developmental Goals, SPSS: Statistical Package for Social Science, WHO: World Health Organization.

Competing interests: The authors declare no competing interests.

Author's contributions: AY conceptualized the study, drafted the manuscript and analyzed the data while TG, DA, ST and BA have critically reviewed the draft for the intellect and rewritten the entire manuscript the way it is currently presented. The authors had approved the final version.

Acknowledgements: First, we would like to express our heartfelt gratitude to study participants for devote their times to answer numerous and private questions and Jinka town public health institutions and South Omo Health Bureau. Secondly we would like to express our deepest gratitude to data collectors for their devotion and patience during the data collection period. Thirdly, Arba Minch University for giving us this chance and financial support and all others those contributes for the success of the study

Funding: School of health science, Arba Minch University. In this study the funders did not have any role in the study design, data collection, analysis or interpretation of the data, or in the writing of the manuscript.

Ethics approval and consent to participate: Ethical clearance and permission was obtained from the Ethical review committee of Arba Minch University, college of medicine and health Science (CMHS/AMU) with institutional ethical review board (IRB) ref no. CMHS/11164/111 and informed verbal consent were obtained from participants who were above age 18 and written consent was taken from their parents for participants who were under the age of 18 after the necessary explanation about the objectives, the purpose, benefits and risks of the study and also their right on decision of participating in the study. Also, the study subjects were informed that information is coded and only used for research purpose. The assurance of confidentiality were performed by omitting name of the study participants from the questionnaire, by telling the safety of the place where the questionnaire was stored after data collection. For participants identified with depressive symptoms were advised to visit the psychiatric clinic for better evaluation and treatment.

Consent for publication: Not applicable 
Availability of data and supporting material: The datasets used and analyzed during the current study are available from the corresponding author on reasonable request.

\section{References}

1.WHO: depression as global concern. world health report 2012.

2.Shidhaye PR GP: Maternal depression: A hidden burden in developing countries. Annals of Medical and Health Sciences Research 2014, 4 (4):463-465.

3.FMOH: National Mental Health Strategy of Ethiopia,Addis Abeba. 2012.

4.Cunningham FG: Williams Obstetrics 24th edition McGraw-Hill Education. In: psycatric disorders. Medical; 2014.

5.who WHOUNPf: Mental health aspects of women's reproductive health,. Geneva,. a global review of literature 2009.

6.Rahman A, Iqbal Z, Bunn J, Lovel H, Harrington R: Impact of maternal depression on infant nutritional status and illness: a cohort study. Archives of general psychiatry 2004, 61(9):946-952.

7.Bonari L, Pinto N, Ahn E, Einarson A, Steiner M, Koren G: Perinatal risks of untreated depression during pregnancy. The Canadian Journal of Psychiatry 2004, 49(11):726-735.

8.Hanlon C: A Screening for Antenatal depression: a formative study for development of a perinatal mental health liaison service in Zewditu hospital. Addis Ababa University; 2014.

9.Rahman A, Bunn J, Lovel H, Creed F: Association between antenatal depression and low birthweight in a developing country. Acta Psychiatrica Scandinavica 2007, 115(6):481-486.

10.Marzuk PM, Tardiff K, Leon AC, Hirsch CS, Portera L, Hartwell N, lqbal MI: Lower risk of suicide during pregnancy. American Journal of Psychiatry 1997, 154(1):122-123.

11.Organization WH: Health in 2015: from MDGs, millennium development goals to SDGs, sustainable development goals. 2015.

12.Ayele TA, Azale T, Alemu K, Abdissa Z, Mulat H, Fekadu A: Prevalence and Associated Factors of Antenatal Depression among Women Attending Antenatal Care Service at Gondar University Hospital, Northwest Ethiopia. PloS one 2016, 11(5):e0155125.

13.Beck AT SR, Brown GK.: Beck depression inventory-II. 1996, 78(2):490.

14.al De: Redrawn questionnaire, OSS -3 wording and scoring 2006 ((2)). 
15.Thompson 0, Ajayi I: Prevalence of antenatal depression and associated risk factors among pregnant women attending antenatal clinics in Abeokuta North Local Government Area, Nigeria. Depression research and treatment 2016, 2016.

16.Biratu A, Haile D: Prevalence of antenatal depression and associated factors among pregnant women in Addis Ababa, Ethiopia: a cross-sectional study. Reproductive health 2015, 12(1):99.

17.Pereira PK LG, Pilowsky DL, Lima LA, Legay LF.: Depression during pregnancy: prevalence and risk factors among women attending a public health clinic in Rio de Janeiro, Brazil. Cadernos de Saúde Pública. 2009, 12.2725-2736.

18.Ajinkya S, Jadhav PR, Srivastava NN: Depression during pregnancy: Prevalence and obstetric risk factors among pregnant women attending a tertiary care hospital in Navi Mumbai. Industrial psychiatry journal 2013, 22(1):37.

19.Lee AM, Lam SK, Lau SMSM, Chong CSY, Chui HW, Fong DYT: Prevalence, course, and risk factors for antenatal anxiety and depression. Obstetrics \& Gynecology 2007, 110(5):1102-1112.

20.Dagklis T, Papazisis G, Tsakiridis I, Chouliara F, Mamopoulos A, Rousso D: Prevalence of antenatal depression and associated factors among pregnant women hospitalized in a high-risk pregnancy unit in Greece. Social psychiatry and psychiatric epidemiology 2016, 51(7):1025-1031.

21.Rwakarema M, Premji SS, Nyanza EC, Riziki P, Palacios-Derflingher L: Antenatal depression is associated with pregnancy-related anxiety, partner relations, and wealth in women in Northern Tanzania: a cross-sectional study. BMC women's health 2015, 15(1):68.

22.Mossie TB, Sibhatu AK, Dargie A, Ayele AD: Prevalence of antenatal depressive symptoms and associated factors among pregnant women in Maichew, North Ethiopia: an institution based study. Ethiopian journal of health sciences 2017, 27(1):59-66.

23.Sahile MA, Segni MT, Awoke T, Bekele D: Prevalence and predictors of antenatal depressive symptoms among women attending Adama Hospital Antenatal Clinic, Adama, Ethiopia. International Journal of Nursing and Midwifery 2017, 9(5):58-64.

24.Bitew T, Hanlon C, Kebede E, Medhin G, Fekadu A: Antenatal depressive symptoms and maternal health care utilisation: a population-based study of pregnant women in Ethiopia. BMC pregnancy and childbirth 2016, 16(1):301.

25.Gebremichael G, Yihune M, Ajema D, Haftu D, Gedamu G: Perinatal Depression and Associated Factors among Mothers in Southern Ethiopia: Evidence from Arba Minch Zuria Health and Demographic Surveillance Site. Psychiatry journal 2018, 2018.

26.World Health Organization UNPF, Key Centre for Women's Health in Society.: Mental health aspects of women's reproductive health: a global review of the literature. World Health Organization 2009. 
27.Pourreza A, Batebi A: Psychological consequences of abortion among the post abortion care seeking women in Tehran. Iranian journal of psychiatry 2011, 6(1):31.

28.Laursen M, Johansen C, Hedegaard M: Fear of childbirth and risk for birth complications in nulliparous women in the Danish National Birth Cohort. BJOG: An International Journal of Obstetrics \& Gynaecology 2009, 116(10):1350-1355.

\section{Tables}

\section{Tables}

Table 1: Socio demographic characteristics of pregnant mothers at Jinka public health facilities, from June 01 to June 30, 2018.

\begin{tabular}{|c|c|c|c|}
\hline \multicolumn{2}{|c|}{ Socio-demographic characteristics } & Frequency & Percentage \\
\hline \multirow[t]{5}{*}{ Age } & $15-19$ & 57 & 12.8 \\
\hline & $20-24$ & 191 & 42.8 \\
\hline & $25-29$ & 136 & 30.5 \\
\hline & $30-35$ & 49 & 11 \\
\hline & $\geq 35$ & 13 & 2.9 \\
\hline \multirow[t]{4}{*}{ Religion } & Orthodox & 172 & 38.6 \\
\hline & Protestant & 210 & 47.1 \\
\hline & Muslim & 54 & 12.1 \\
\hline & Others & 10 & 2.2 \\
\hline \multirow[t]{5}{*}{ Occupation } & House wife & 267 & 59.9 \\
\hline & Merchant & 59 & 13.2 \\
\hline & Government employed & 79 & 17.7 \\
\hline & Daily workers & 14 & 3.1 \\
\hline & Student & 12 & 2.7 \\
\hline \multirow[t]{4}{*}{ Educational status } & Unable read and write & 126 & 28.3 \\
\hline & Grade 1-8 & 156 & 35 \\
\hline & Grade 9-12 & 89 & 20 \\
\hline & College or university & 75 & 16.7 \\
\hline \multirow[t]{4}{*}{ Marital status } & Married & 422 & 94.6 \\
\hline & single & 10 & 2.2 \\
\hline & Separated/divorced & 10 & 2.2 \\
\hline & Widowed & 4 & 1 \\
\hline
\end{tabular}


Table 2: Obstetric and other health related characteristics of pregnant mothers at Jinka public health facilities, from June 01 to June 30, 2018.

\begin{tabular}{llll}
\hline \multicolumn{1}{c}{ Variables } & & Frequency & Percentage \\
Gravida & 1 & 140 & 31.4 \\
& $2-4$ & 249 & 55.8 \\
Parity & 5 and above & 57 & 12.8 \\
Trimester of pregnancy & Primigravida & 140 & 31.4 \\
& Multigravida & 306 & 68.6 \\
Planned pregnancy & First & 58 & 13.0 \\
& Second & 177 & 39.7 \\
History of abortion & Third & 211 & 47.3 \\
Complication in current pregnancy & Yes & 410 & 91.9 \\
& No & 36 & 8.1 \\
Complication in previous pregnancy & Yes & 45 & 85 \\
& No & 261 & 15 \\
& Yes & 1 & 0.2 \\
Complication in previous labour and delivery & Yes & 445 & 99.2 \\
& No & 16 & 10.5 \\
& Yes & 32 & 89.5 \\
\hline
\end{tabular}

Table 3: Psychosocial factors of pregnant mothers at Jinka public health facilities, from June 01 to June 30, 2018 


\begin{tabular}{|l|l|l|l|}
\hline \multicolumn{2}{|l|}{ Variables } & Frequency & Percentage \\
\hline Oslo social support scale & $3-8$ & 9 & 2 \\
\cline { 2 - 4 } & $9-11$ & 66 & 14.8 \\
\cline { 2 - 4 } & $12-14$ & 371 & 83.2 \\
\hline Husband feeling on pregnancy & Happy & 412 & 92.4 \\
\cline { 2 - 4 } & $\begin{array}{l}\text { Not } \\
\text { happy }\end{array}$ & 34 & 7.6 \\
\hline \multirow{2}{*}{$\begin{array}{l}\text { Fear of pregnancy and delivery related } \\
\text { complication }\end{array}$} & Yes & 111 & 24.9 \\
\cline { 2 - 4 } & No & 335 & 75.1 \\
\hline
\end{tabular}

Table 4: Bi-variable and multi-variable logistic regression analysis for association between antenatal depression and different independent factors. 


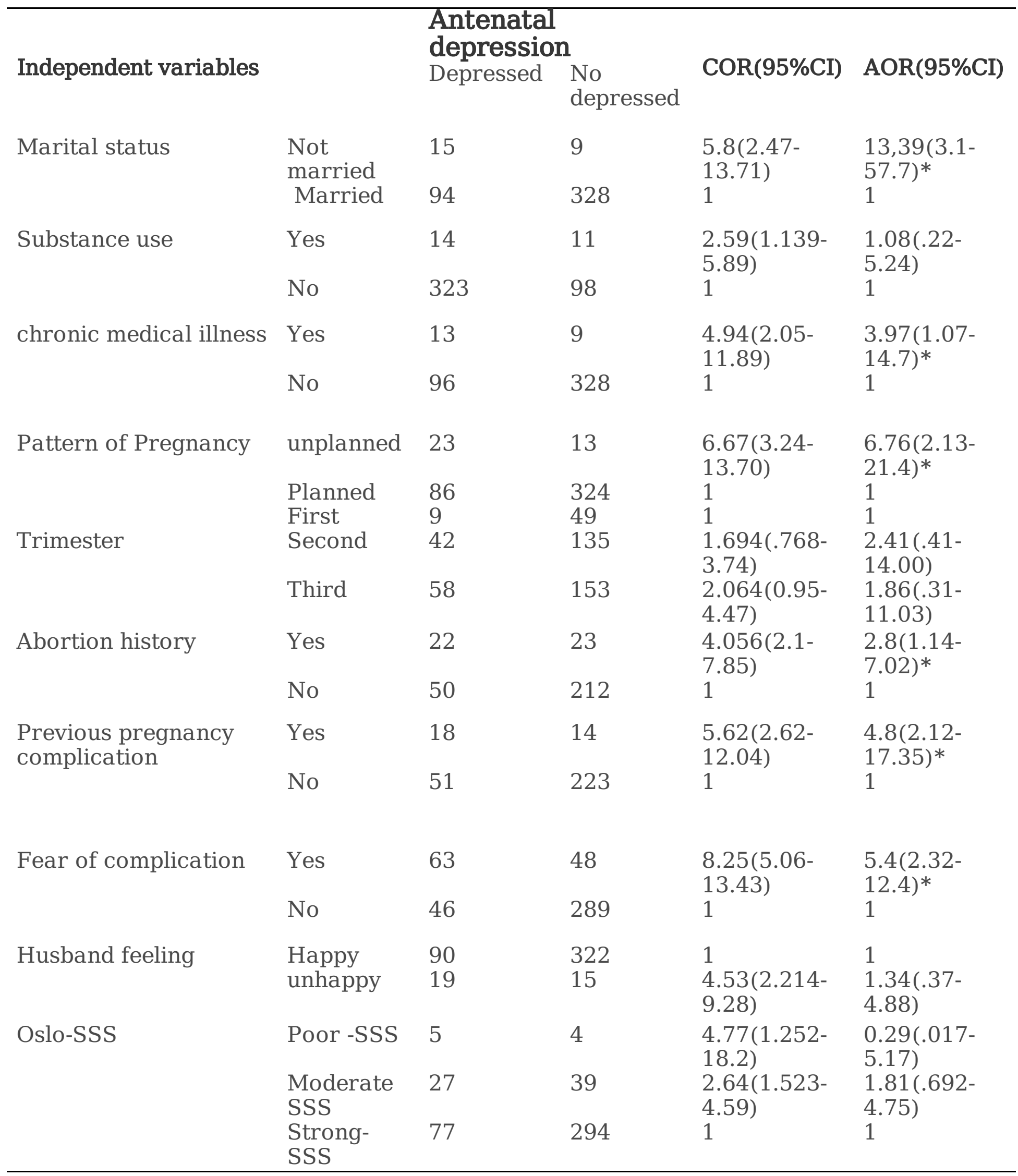

From the table above those have * shows that variables which had significant association with antenatal depression in multivariate logistic regression. 


\section{Figures}

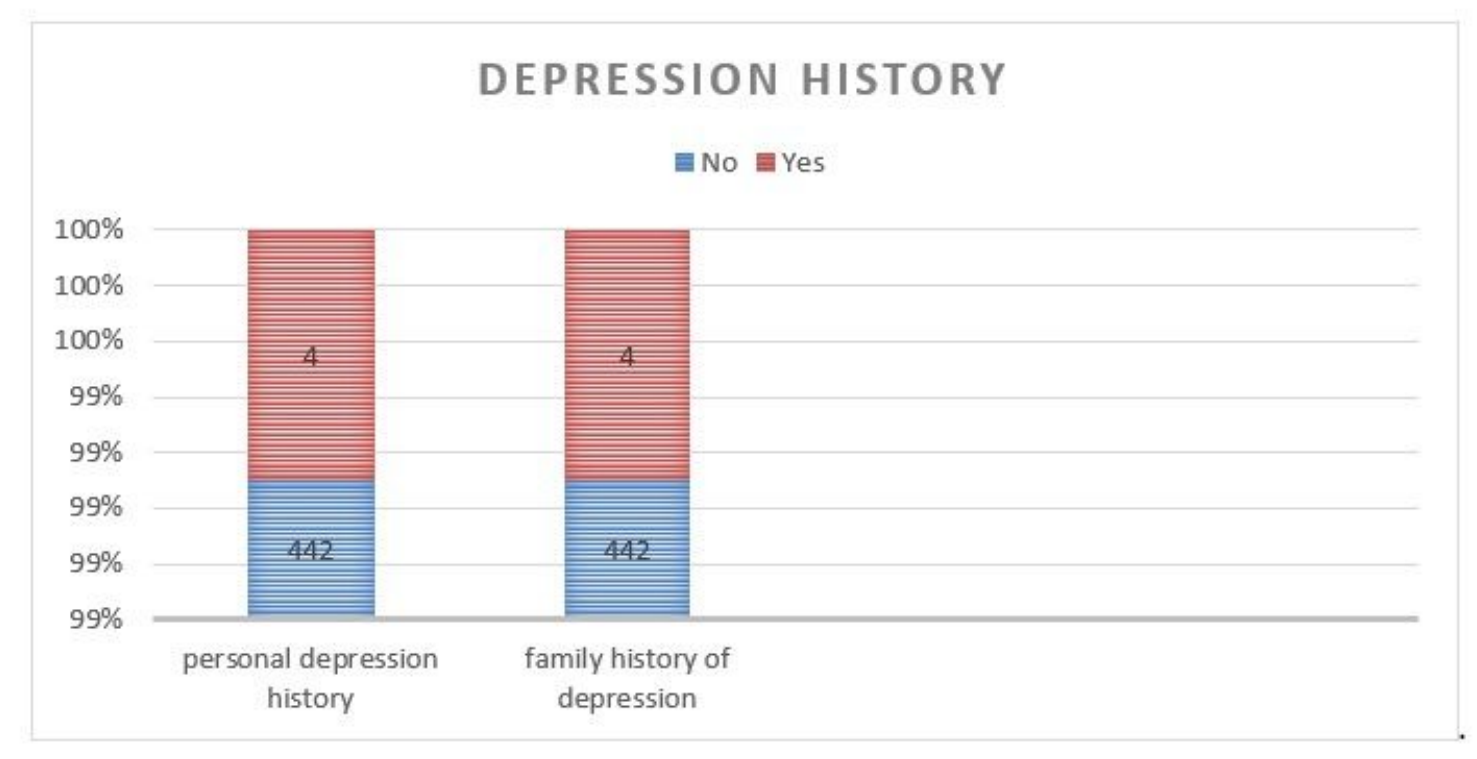

Figure 1: Depression history of pregnant mothers at Jinka public health facilities, from June 01 to June 30, 2018.

\section{Figure 1}

Depression history of pregnant mothers at Jinka public health facilities, from June 01 to June 30, 2018. 


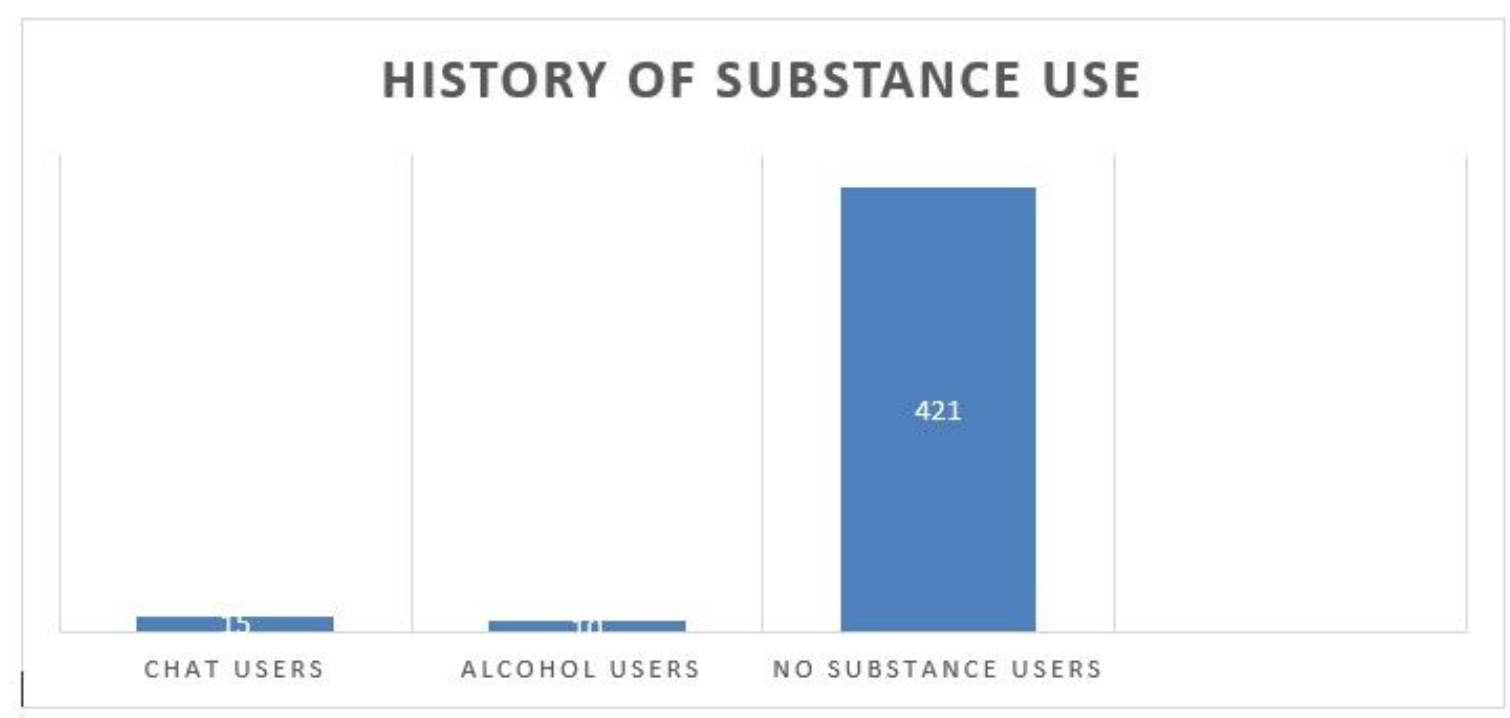

Figure 2: History of substance use among pregnant mothers at Jinka public health facilities, from June 01 to June 30, 2018.

\section{Figure 2}

History of substance use among pregnant mothers at Jinka public health facilities, from June 01 to June 30, 2018.

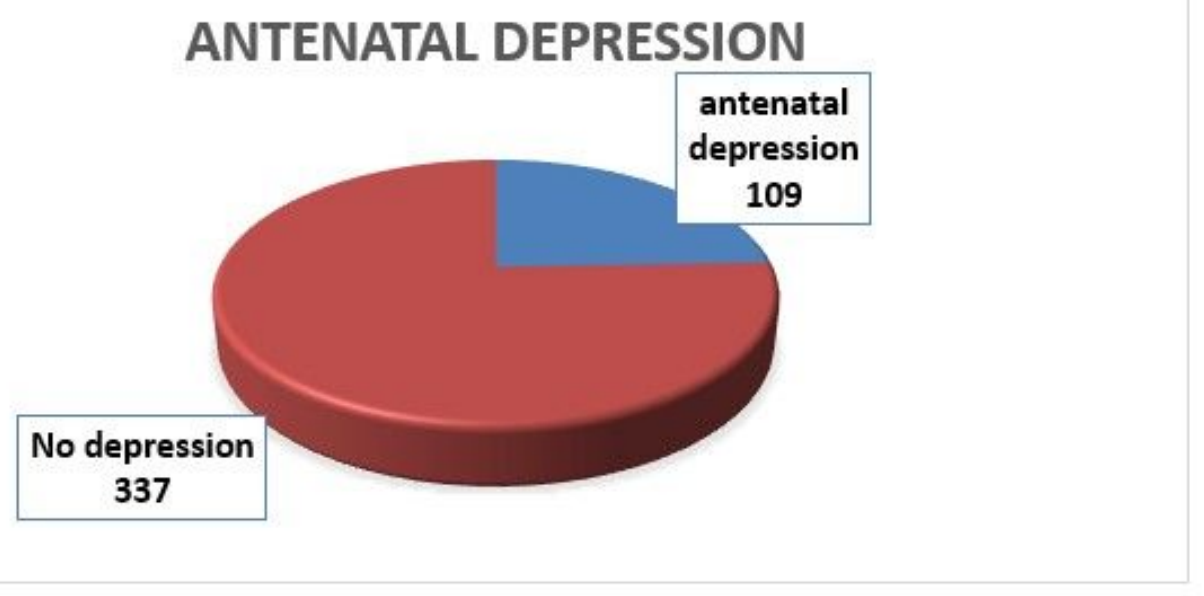

Figure 3: Magnitude of antenatal depression among pregnant mothers at Jinka public health facilities, from June 01 to June 30, 2018. 
Figure 3

Magnitude of antenatal depression among pregnant mothers at Jinka public health facilities, from June 01 to June 30, 2018.

\section{Supplementary Files}

This is a list of supplementary files associated with this preprint. Click to download.

- EnglishversionQuestionnaire.docx

- STROBE.doc 